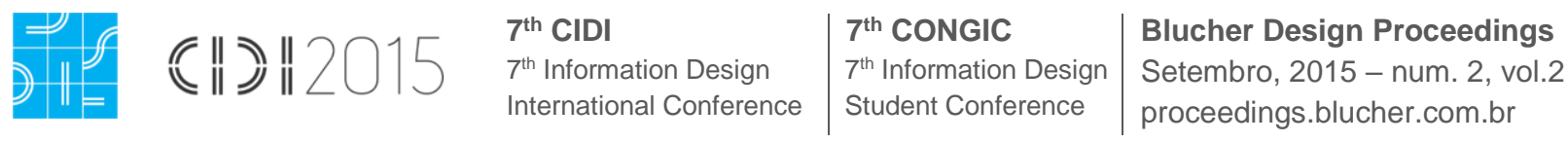

\title{
Levantamento bibliográfico: análise comparativa entre metodologias de design da informação e jogos didáticos e não didáticos de tabuleiro Bibliographical survey: comparative analysis between information design methodologies and educational and noneducational board games
}

\author{
Giselle Araújo, Yelitza López, Solange Coutinho
}

metodologia; design da informação; design de jogos

\begin{abstract}
Este artigo apresenta uma análise comparativa entre algumas metodologias de desenvolvimento de jogos didáticos e não didáticos, especificamente os jogos de tabuleiro, com as metodologias de design da informação propostas por Redish (2000), Sless (2005) e Simlinger (2007), buscando identificar a inserção do design da informação nesse processo. Foram analisadas, por meio de quadro comparativo, três metodologias utilizadas para desenvolvimento de jogos didáticos: Carneiro \& Lopes (2007), Mendes et.al (2009) e Medeiros (2013), bem como dois métodos utilizados para jogos não didáticos: Albuquerque (2010) e CTCD (2013). A presente pesquisa tem caráter bibliográfico, exploratório e analítico, portanto, localiza-se numa perspectiva subjetiva.
\end{abstract}

methodology; information design, game design

This article presents a comparative analysis of methodologies for developing educational and noneducational games, specifically board games, and information design methodologies proposed by Redish (2000), Sless (2005) and Simlinger (2007), seeking to identify the inclusion of information design in the process. With the aid of a comparative framework, we analysed three methodologies used to develop educational games: Carneiro \& Lopes (2007), Mendes et al. (2009) and Medeiros (2013), as well as two methodologies for noneducational games: Albuquerque (2010) and CTCD (2013). The nature of this study is bibliographical, exploratory and analytical, although viewed from a subjective perspective.

\section{Introdução}

Metodologia é em termos gerais a organização do trabalho, uma forma de guiar e ter controle sobre o processo de desenvolvimento de um projeto, que vai determinando cada etapa a ser seguida. No campo de design especificamente, Bomfim (1995) define que a metodologia é a ciência que se ocupa do estudo de métodos, técnicas ou ferramentas e de suas aplicações na definição, organização e solução de problemas teóricos e práticos, sendo a Metodologia de Design, a disciplina que se ocupa da aplicação de métodos a problemas específicos e concretos.

Em se tratando de design da informação, é importante a utilização de metodologias que ajudem a guiar o processo de design nesta área, com o objetivo de conseguir sucesso nos resultados e contribuições para futuros projetos. No desenvolvimento de métodos para criação de jogos de tabuleiro, faz-se necessário o cruzamento das metodologias utilizadas nos dois campos do design.

G. Araújo, Y. López, S. Coutinho. 2015. Levantamento bibliográfico: análise comparativa entre metodologias de design da informação e jogos didáticos e não didáticos de tabuleiro. In: C. G. Spinillo; L. M. Fadel; V. T. Souto; T. B. P. Silva \& R. J. Camara (Eds). Anais [Oral] do $7^{\circ}$ Congresso Internacional de Design da Informação/Proceedings [Oral] of the 7th Information Design International Conference | CIDI 2015 [Blucher Design Proceedings, num.2, vol.2]. São Paulo: Blucher, 2015. ISSN 2318-6968, DOI 10.5151/designpro-CIDI2015-cidi_386 
Este estudo objetivou apresentar uma análise comparativa entre algumas metodologias de desenvolvimento de jogos didáticos e não didáticos, especificamente os jogos de tabuleiro, com as metodologias de design da informação propostas por Redish (2000), Sless (2005) e Simlinger (2007), buscando identificar a inserção do design da informação no processo de elaboração desses jogos. Para isto, se realizou uma pesquisa bibliográfica em sites como da infodesign ${ }^{1}$, utilizando palavras chaves como: jogos, tabuleiros e metodologias, que abordassem metodologias lineares e não lineares e, compará-lo com metodologias de design da informação. É uma pesquisa exploratória e analítica, portanto, localiza-se numa perspectiva subjetiva.

\section{Design da informação}

Conforme Hurlburt (1981) o termo design de informação, é muito amplo em suas conotações, por isso, para nos aproximar da relação proposta neste artigo, abordaremos algumas conceituações para compreender melhor o design da informação e suas respectivas metodologias. Rune Pettersson (2012) postula que design da informação envolve pesquisa, análise, planejamento, apresentação e entendimento do conteúdo, linguagem e forma de uma mensagem. Desta maneira o autor exalta a necessidade de pesquisa e do processo anterior à apresentação das informações para o usuário.

Redish (2002) afirma que design da informação é o "todo", é o que fazemos para desenvolver um documento ou comunicação que trabalha para seus usuários. Esta definição traz dois pontos adicionais para os designers da informação (infodesigners) levar em consideração: (1) na maioria das vezes os usuários estão usando essa informação para atingir uma meta pessoal ou completar uma tarefa; (2) os usuários determinam o tempo e esforço para encontrar e entender a informação que necessitam.

As definições de Pettersson (2012) e Redish (2002) apresentam um contraste, mas também se complementam, pois Pettersson enfatiza a necessidade de pesquisa prévia à apresentação da informação, enquanto Redish direciona para o conhecimento do usuário e, posteriormente, o feedback. Outra definição que se adequa ao propósito deste artigo é a de Horn (1999), o autor define o design da informação como a arte e a ciência de preparar a informação para que possa ser usada pelos seres humanos com eficiência e eficácia, de acordo com o autor, seus principais objetivos são:

- Desenvolver documentos que sejam compreensíveis, de recuperação fácil e com precisão, e que possam ser facilmente traduzidos em ações efetivas;

- Projetar interações com equipamentos da forma mais fácil, natural e agradável possível. Isso envolve resolver vários problemas no design de interface humanocomputador;

- Possibilitar que as pessoas encontrem seus caminhos no espaço tridimensional com conforto e facilidade, especialmente no espaço urbano, mas também, devido a desenvolvimentos recentes, no plano virtual.

Podemos unir esta definição à de Pettersson (2012), pois elas sugerem a compressão da informação e ambas envolvem a importância da pesquisa prévia à apresentação. No processo metodológico para desenvolvimento de jogos de tabuleiro (didáticos e não didáticos), esta pesquisa é relevante, pois os jogos possuem informações, que são importantes para a compreensão do usuário e necessitam ser exibidas, atualizadas, organizadas e realimentadas (Neves et al. 2013).

\footnotetext{
${ }^{1}$ http://www.infodesign.org.br/infodesign

Anais [Oral] do 7º Congresso Internacional de Design da Informação | CIDI 2015

Proceedings [Oral] of the 7th Information Design International Conference / IDIC 2015
} 
A partir das conceituações já expostas, podemos inferir que o design da informação envolve: pesquisa, análise, planejamento, apresentação e entendimento tanto do conteúdo como do usuário para que a informação seja usada com eficiência e eficácia.

\section{Breve panorama sobre jogos de tabuleiro}

O jogo de tabuleiro mais popular do mundo é o Monopoly, cuja versão atual foi publicada em 1935 nos Estados Unidos. Este jogo é conhecido no Brasil como Banco Imobiliário, sendo produzido pela Estrela desde 1940. A mecânica do jogo baseia-se no The Landlord's Game de Elizabeth J. Magie Phillips, criado como uma proposta didática para ensinar a teoria do economista Henry George sobre taxa simples (figura 1).

Figura 1: Jogo Monopoly ou Banco Imobiliário. Fonte: http://www.abril.com.br/fotos/jogos-tabuleiro/ acessado em $17 / 07 / 14$

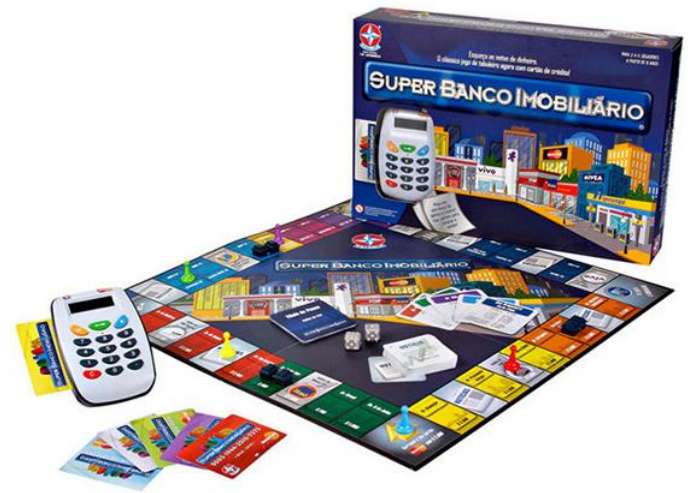

$\mathrm{O}$ ato de jogar, possibilitando o envolvimento e vivência em realidades artificiais é um atrativo comum dos homens desde o princípio da civilização. Ao longo da história, vem se desenvolvendo uma infinita variedade de jogos de tabuleiro, que refletem sua lógica e raciocínio, contribuindo para o entendimento de grupos sociais em relação ao seu próprio ambiente. Neste contexto, assim como o Banco Imobiliário criado com finalidade de ensino, incluem-se os jogos didáticos que estão cada dia, mais presentes nos processos de ensino e aprendizagem, sejam na educação da modalidade presencial ou a distância, esses artefatos são aplicados em diversas áreas do conhecimento e para diferentes faixas etárias. Isso se dá pelo fato de um jogo ser capaz de contribuir no desenvolvimento motor, psicológico, físico, intelectual e social do indivíduo.

O papel do designer no desenvolvimento de um jogo é bem amplo, ele pode ser responsável pelo direcionamento e criação de fases, cenários, personagens, sons, desafios entre outras etapas. Durante este processo, a principal vertente não está simplesmente na estética, mas nos componentes informacionais que irão auxiliar o jogador. As informações disponíveis no jogo precisam contribuir, de maneira clara e objetiva, para que o jogador encontre aquilo que ele precisa para atingir o seu objetivo. Diante do exposto, entende-se que o design da informação aplica-se à metodologia para melhorar o processo de comunicação, conduzindo o desenvolvimento do artefato de acordo com as necessidades dos usuários aos qual o jogo está destinado.

\section{Metodologias em Infodesign e metodologia em Design de Jogos}

$\mathrm{Na}$ área de design da informação, alguns autores têm proposto metodologias para o desenvolvimento de projetos. Por tanto, as metodologias tem sofrido transformações ao longo do tempo, diferentes formas de pensar e olhares enquanto estruturas. O quadro a seguir apresenta

Anais [Oral] do 7º Congresso Internacional de Design da Informação | CIDI 2015

Proceedings [Oral] of the 7th Information Design International Conference / IDIC 2015 
três modelos metodológicos em infodesign, os esquemas que eles trazem são classificados segundo Bomfim (1995) como cíclicos, quer dizer não lineares e com retornos, o que significa feedbacks.

Quadro 1: Metodologias em Infodesign

\begin{tabular}{|c|c|c|c|}
\hline Etapa & Redish (2000) & Sless (2005) & Simlinger (2007) \\
\hline 1 & $\begin{array}{l}\text { Planejamento da } \\
\text { informação } \\
\text { Que pretende alcançar? } \\
\text { Quem vai usar? } \\
\text { Como vão usar? } \\
\text { Onde vão usar? } \\
\text { Que informação eles } \\
\text { precisam? }\end{array}$ & $\begin{array}{l}\text { Escopo ou delimitação } \\
\text { Identificar todos os fatores } \\
\text { necessários que se devem } \\
\text { levar em consideração quando } \\
\text { se projeta, tais como: contexto } \\
\text { socioeconômico e politico, } \\
\text { requisitos técnicos e legais. }\end{array}$ & $\begin{array}{l}\text { Familiarização com o tema } \\
\text { Desbloquear a informação a ser } \\
\text { projetada. } \\
\text { Se familiarizar com o significado } \\
\text { da informação e o ambiente } \\
\text { onde ele pretende ser } \\
\text { apresentado, o designer } \\
\text { também precisa compreender o } \\
\text { propósito da informação. }\end{array}$ \\
\hline 2 & $\begin{array}{l}\text { Planejamento do projeto } \\
\text { Cronograma. } \\
\text { Orçamento. } \\
\text { Time de produção. } \\
\text { Padronização de estilos. } \\
\text { Atividade de usabilidade. }\end{array}$ & $\begin{array}{l}\text { Diagnóstico e análise } \\
\text { Diagnosticar e analisar erros } \\
\text { para descobrir como a } \\
\text { informação existente está em } \\
\text { relação aos requisitos de } \\
\text { desempenho definidos na fase } \\
\text { de escopo e delimitação. }\end{array}$ & $\begin{array}{l}\text { Familiarização com o usuário } \\
\text { Determinar o que é critico para } \\
\text { o usuário a partir de entrevistas } \\
\text { e investigações. } \\
\text { Desenvolver cenários onde } \\
\text { "personas" realizam as } \\
\text { atividades/ações que a } \\
\text { informação deverá facilitar. }\end{array}$ \\
\hline 3 & $\begin{array}{l}\text { Seleção de conteúdo/ } \\
\text { organização } \\
\text { Reunir a informação. } \\
\text { Selecionar o conteúdo. } \\
\text { Organizar o material. } \\
\text { Preparar um esboço. } \\
\text { Plano de layout de cada } \\
\text { página ou tela. } \\
\text { Teste de organização e } \\
\text { layouts com usuários. } \\
\text { Revisão baseada em teste } \\
\text { de usabilidade. }\end{array}$ & $\begin{array}{l}\text { Projeto } \\
\text { Usando tipografia, gráficos, } \\
\text { cores, linguagem, estrutura e } \\
\text { outros recursos, para que a } \\
\text { informação seja apresentada } \\
\text { conforme os requisitos. }\end{array}$ & $\begin{array}{l}\text { Proposta } \\
\text { O designer da informação está } \\
\text { pronto para fazer a proposta } \\
\text { que descreve o trabalho. } \\
\text { Resultado a ser alcançado. } \\
\text { Tempo e dinheiro a ser } \\
\text { investido. }\end{array}$ \\
\hline 4 & $\begin{array}{l}\text { Esboço e teste } \\
\text { Primeiro esboço. } \\
\text { Produção estética. } \\
\text { Trabalhar com texto e } \\
\text { imagem. Teste de esboços } \\
\text { com os usuários. } \\
\text { Revisão e complemento. } \\
\text { Melhorar consistência e } \\
\text { usabilidade. Testar e repetir } \\
\text { o processo, até que o } \\
\text { documento seja concluído e } \\
\text { funcione para os usuários. }\end{array}$ & $\begin{array}{l}\text { Teste } \\
\text { Testar, analisar e diagnosticar } \\
\text { para descubrir como a nova } \\
\text { informação está funcionando } \\
\text { em relação aos requisitos de } \\
\text { desempenho definidos na fase } \\
\text { de delimitação. }\end{array}$ & $\begin{array}{l}\text { Projeto } \\
\text { Compor a informação utilizando } \\
\text { elementos verbais, pictóricos, } \\
\text { acústicos, táteis e olfativos. } \\
\text { Definição, planejamento e } \\
\text { modelação do conteúdo da } \\
\text { mensagem e dos ambientes em } \\
\text { que ele será apresentado. }\end{array}$ \\
\hline 5 & $\begin{array}{l}\text { Produção final } \\
\text { Nova revisão } \\
\text { Saber qual tecnologia é } \\
\text { necessáriaantes do } \\
\end{array}$ & $\begin{array}{l}\text { Redefinição } \\
\text { Usando tipografia, gráficos, } \\
\text { cores, linguagem, estrutura e } \\
\text { outros recursos, para remover }\end{array}$ & $\begin{array}{l}\text { Avaliação } \\
\text { Os objetivos das tarefas } \\
\text { relacionadas com a transferên- } \\
\text { cia de conhecimento foram } \\
\text { alcançadas? Produziram o }\end{array}$ \\
\hline
\end{tabular}

Anais [Oral] do 7º Congresso Internacional de Design da Informação | CIDI 2015 


\begin{tabular}{l|l|l|l}
\hline & $\begin{array}{l}\text { lançamento. } \\
\text { Produção e lançamento }\end{array}$ & erros nas informações. & $\begin{array}{l}\text { efeito desejado? Utilizar insights } \\
\text { da psicologia cognitiva para } \\
\text { conduzir entrevistas com } \\
\text { usuários, aplicar métodos de } \\
\text { avaliação, e interpretar os } \\
\text { resultados. }\end{array}$ \\
\hline 6 & $\begin{array}{l}\text { Continuação do processo } \\
\text { Colhendo feedback. } \\
\text { Usando feedback para } \\
\text { revisão. } \\
\text { Manter atualizado. }\end{array}$ & $\begin{array}{l}\text { Implementação } \\
\text { Desenvolver uma solução de } \\
\text { projeto e se assegurar que os } \\
\text { desenhos finais são } \\
\text { implementados na produção, } \\
\text { com a aprovação de todos os } \\
\text { interessados. }\end{array}$ & $\begin{array}{l}\text { Redefinão e implementação } \\
\text { da informação } \\
\text { Com base nos insight, otimizar o } \\
\text { conteúdo de design, considerar } \\
\text { alternativas ou identificar os } \\
\text { obstáculos que podam ser } \\
\text { superados com uma mudança } \\
\text { de direção. Auxiliar na } \\
\text { implementação do design e, se } \\
\text { necessário, realizar ajustes e } \\
\text { modificações. }\end{array}$ \\
\hline 7 & - & $\begin{array}{l}\text { Monitoramento } \\
\text { Medição para garantir que o } \\
\text { desempenho da informação é } \\
\text { mantido durante a sua } \\
\text { utilização e recolher dados } \\
\text { para sua melhoria. }\end{array}$ & \\
\hline
\end{tabular}

A metodologia proposta por Redish (2000) é o resultado de várias atualizações ao modelo inicial que tinha sido elaborado no ano 1978, baseada na experiência, conversações com colegas e clientes, que a fizeram mais apropriada às diferentes mídias. A metodologia proposta se compõe de seis etapas principalmente, destacando a importância das questões de planejamento e análise, o papel da interação e o fato de que as orientações dependem das respostas às perguntas de planejamento, pois todos os projetos são diferentes. A estrutura do modelo é interativo, quer dizer que não é especificamente linear; ressalta feedbacks nas etapas 3-1, 6-1 e 4-3, quantas vezes for necessário.

Sless (2005) difere do método de Redish (2000) por apresentar uma metodologia com sete etapas onde enfatiza no desempenho da informação durante todo o processo e os testes de diagnóstico nas etapas 2, 4, 5 e 7 como requisito para uma boa prática do método e sucesso em infodesign. A metodologia apresentada está voltada a um processo de construção da informação aliado ao conhecimento do usuário, suas motivações e anseios para que a informação seja efetivada, tendo em conta o contexto social em que ele está inserido.

Para Simlinger (2007) no design da informação acontece o mesmo que com os materiais de construção, para lograr um projeto eficiente e de produção, se requer conceitos e planos para atingir o propósito, pois não é suficiente ter máquinas de impressão e toneladas de informação, a fim de criar informação útil, o mesmo que o equipamento de construção não pode criar por si só, espaços humanos utilizáveis.

Esta metodologia apresentada por Simlinger (2007), é um processo de seis etapas não linear com constantes feedbacks, tais como: 3-1, 3-2, 5-4, 6-4. Além disso, exalta o usuário e o uso, como parte das preocupações para o infodesigner, e as exigências sobre o design da informação como: o conteúdo, a cognição e a técnica.

Por outro lado, de acordo com as pesquisas realizadas, as metodologias utilizadas no desenvolvimento de jogos de tabuleiro, em geral, se aproximam das metodologias projetuais, lineares, no campo do design de produto ou industrial, baseadas em diversos autores que apresentam e validam esses métodos em diversas obras.

Anais [Oral] do 7º Congresso Internacional de Design da Informação | CIDI 2015 
Quando se trata especificamente de jogos didáticos, os métodos empregados são desenvolvidos por professores conforme as áreas de atuação dos mesmos, sem um modelo e/ou direcionamento específicos, como se pode observar no quadro e descrições a seguir, na Figura 2:

Figura 2: Metodologias de Jogos Didáticos

\begin{tabular}{|c|l|l|l|}
\hline Etapa & $\begin{array}{l}\text { Design e semiótica: a } \\
\text { criação de jogos de tabu- } \\
\text { leiro como objetos de apren } \\
\text { dizagem. (Medeiros, 2013). }\end{array}$ & $\begin{array}{l}\text { Desenvolvimento de jogos } \\
\text { didáticos para as aulas de } \\
\text { química geral do primeiro ano } \\
\text { do ensino médio. (Mendes et } \\
\text { al., 2009). }\end{array}$ & $\begin{array}{l}\text { O jogo "Ciclo das rochas" } \\
\text { para ensino de Geociên- } \\
\text { cias. (Carneiro \& Lopes, } \\
\text { 2007) }\end{array}$ \\
\hline 1 & $\begin{array}{l}\text { Sintese de conteúdo e } \\
\text { brainstorm }\end{array}$ & $\begin{array}{l}\text { Elaboração de questionário - } \\
\text { levantamento sobre o "problema" }\end{array}$ & $\begin{array}{l}\text { Definição do público-alvo e } \\
\text { tema central }\end{array}$ \\
\hline 2 & $\begin{array}{l}\text { Definição de regras e } \\
\text { objetivos }\end{array}$ & Análise de dados do questionário & $\begin{array}{l}\text { Criação e desenvolvimento } \\
\text { de um protótipo }\end{array}$ \\
\hline 3 & $\begin{array}{l}\text { Confecção dos jogos } \\
\text { Definição dos conteúdos a } \\
\text { serem trabalhados }\end{array}$ & $\begin{array}{l}\text { Formulação de modelo de } \\
\text { estrutura de jogo }\end{array}$ \\
\hline 5 & Apresentação & Desenvolvimento do jogo & $\begin{array}{l}\text { Desenvolvimento de } \\
\text { materiais de suporte }\end{array}$ \\
\hline 6 & - & Aplicação do jogo & $\begin{array}{l}\text { Definição das regras de } \\
\text { funcionamento }\end{array}$ \\
\hline
\end{tabular}

Na primeira pesquisa (Medeiros, 2013), realizada de maio a junho de 2012 como resultado da disciplina de semiótica de um curso de graduação em design gráfico da Faculdade SATC - Santa Catarina, os estudantes foram divididos em cinco grupos com o propósito de desenvolver um jogo de tabuleiro relacionado a conteúdos específicos da semiótica, trabalhados em sala de aula no prazo de três semanas. A cada etapa, o professor da disciplina, então pesquisador, acompanhava e orientava o desenvolvimento dos projetos, porém, os estudantes tinham a liberdade para tomar decisões e definir qual direcionamento seguiriam.

Ao final do processo, apesar das propostas apresentadas obterem resultado satisfatório, cumprindo o objetivo de ensinar os conteúdos das aulas de semiótica de maneira lúdica, observou-se que faltou um método destinado à criação de um jogo de tabuleiro, comprometendo até a realização das primeiras etapas de alguns grupos, no que concerne especificamente à jogabilidade.

A segunda pesquisa (Mendes et al., 2009), tinha como propósito o desenvolvimento de jogo de tabuleiro, didático, para o ensino de química. Foi elaborado um questionário para identificação dos conteúdos que mais necessitavam de uma atividade complementar ao ensino em sala de aula, visando facilitar o processo de ensino e aprendizagem. Em seguida, foram analisados os questionários e identificados quais dos conteúdos já haviam sido trabalhados em sala, chegando à definição de três assuntos específicos para desenvolvimento do jogo. $O$ desenvolvimento do jogo, em si, não foi descrito na pesquisa sendo apenas relatado o processo de aplicação para estudantes do primeiro ano do IFMA. O Processo de avaliação foi feito por meio de questionários, antes e depois da aplicação do jogo, com a finalidade de comprovar a eficácia da utilização do artefato.

No terceiro trabalho (Carneiro \& Lopes, 2007), apresenta-se o desenvolvimento do jogo didático "O Ciclo das Rochas", desenvolvido com o intuito de apoiar a aplicação, produção e 
difusão de conceitos de geociências, para disciplina introdutória de geologia no ensino superior da Unicamp. Das três, esta foi a pesquisa que seguiu um modelo metodológico cujas etapas são descritas em Lopes (2007) e Carneiro \& Lopes (2007). Na etapa 1, foram definidas as diretrizes pedagógicas, público-alvo e tema a ser desenvolvido. Nesta etapa, também se pensou nas regras, níveis e dinâmica do jogo para atender o maior número possível de estudantes, desde o básico até o avançado. Este projeto, dos pesquisados, foi o que destacou o termo design como parte constante na metodologia, pois, ainda na primeira etapa, descreve-se a preocupação com o design, elementos físicos e gráficos do artefato. Houve a preocupação em fazer um levantamento bibliográfico para definição do método a ser empregado no desenvolvimento do projeto, conforme podemos observar no esquema proposto pelos autores (figura 3):

Figura 3: Fluxograma de criação de jogos em geral (Carneiro \& Lopes 2007).

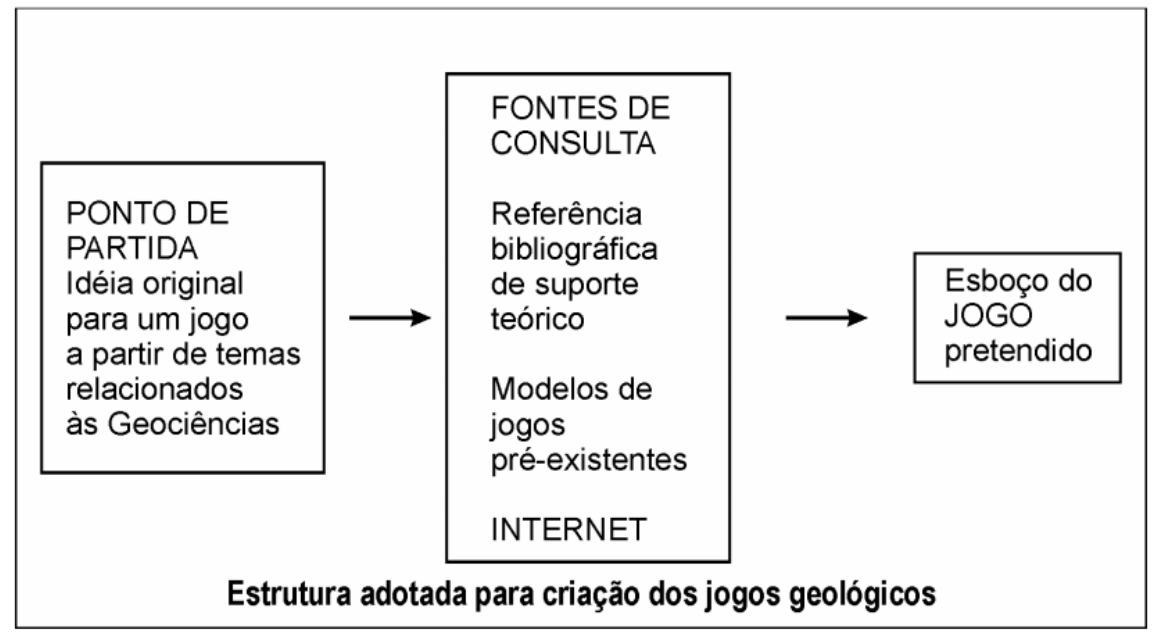

$\mathrm{Na}$ etapa seguinte, foram esboçadas algumas alternativas buscando atingir os objetivos psicopedagógicos definidos na etapa $1 \mathrm{e}$, para isso, fez-se necessário reunir diferentes estilos de jogos conforme a classificação levantada nas pesquisas indicadas na figura 2 . Em seguida, nas etapas 3 e 4, foi desenvolvido um protótipo com dois modelos de estrutura de tabuleiro para atender aos três níveis (básico, intermediário e avançado) de estudantes, por ser um jogo direcionado à fixação de conceitos. Na etapa 5 , houve a definição e descrição detalhada das regras e dinâmica do jogo e, na última etapa, o jogo foi aplicado a estudantes do primeiro ano do curso de Ciências da Terra da Unicamp em 2006. Verificou-se que os resultados foram positivos, que o público-alvo poderia ser ampliado para as áreas afins como química e biologia, além da identificação de algumas correções necessárias para novos testes.

Após estas análises, observa-se que, de maneira geral, não existe um padrão metodológico a ser seguido para desenvolvimento de jogos didáticos de tabuleiro. Em outras referências, tratando apenas de jogos de tabuleiro, observamos as metodologias empregadas no desenvolvimento de dois jogos, desenvolvidos por estudantes do curso técnico em comunicação visual (CTCD - Centro Tecnológico de Cultura Digital) e um jogo desenvolvido no curso superior em design gráfico (Faculdades Integradas Barros Melo) para um comparativo entre os processos (figura 4). 
Figura 4: Metodologias de Design de Jogos

\begin{tabular}{|c|c|c|c|}
\hline Etapa & $\begin{array}{l}\text { Projeto de Design: Jogo de } \\
\text { Tabuleiro Playlist (CTCD, } \\
\text { 2013). }\end{array}$ & $\begin{array}{l}\text { Projeto de Design: Jogo de } \\
\text { Tabuleiro Sabe ou não Sabe } \\
\text { (CTCD, 2013). }\end{array}$ & $\begin{array}{l}\text { Simulacro: Criação de um } \\
\text { Jogo de Tabuleiro } \\
\text { (Albuquerque, 2010) }\end{array}$ \\
\hline 1 & $\begin{array}{l}\text { Briefing, brainstorm, escolha } \\
\text { de público-alvo e temática. }\end{array}$ & $\begin{array}{l}\text { Briefing, brainstorm, escolha } \\
\text { de público-alvo e temática. }\end{array}$ & $\begin{array}{l}\text { Briefing, definição de públi- } \\
\text { co-alvo e objetivos. }\end{array}$ \\
\hline 2 & $\begin{array}{l}\text { Pesquisas sobre o universo } \\
\text { do artefato, definição de } \\
\text { conceitos. }\end{array}$ & $\begin{array}{l}\text { Pesquisas sobre o universo do } \\
\text { artefato, definição de } \\
\text { conceitos. }\end{array}$ & Pesquisas de similares \\
\hline 3 & $\begin{array}{l}\text { Laboratório prático, para } \\
\text { formulação de estratégias, } \\
\text { jogabilidade e primeiros } \\
\text { esboços. }\end{array}$ & $\begin{array}{l}\text { Laboratório prático, para } \\
\text { formulação de estratégias, } \\
\text { jogabilidade e primeiros } \\
\text { esboços. }\end{array}$ & $\begin{array}{l}\text { Definição de elementos de } \\
\text { jogo (temática, conceitos, } \\
\text { mecânica e jogabilidade) }\end{array}$ \\
\hline 4 & $\begin{array}{l}\text { Definição de elementos } \\
\text { gráficos (identidade visual) e } \\
\text { compositivos do artefato } \\
\text { (peças e materiais) }\end{array}$ & $\begin{array}{l}\text { Definição de elementos } \\
\text { gráficos (identidade visual) e } \\
\text { compositivos do artefato } \\
\text { (peças e materiais) }\end{array}$ & $\begin{array}{l}\text { Identidade visual (coleta de } \\
\text { dados, geração de ideias, } \\
\text { desenvolvimento da identi- } \\
\text { dade) }\end{array}$ \\
\hline 5 & $\begin{array}{l}\text { Desenvolvimento de protótipo } \\
\text { para testes e ajustes. }\end{array}$ & $\begin{array}{l}\text { Desenvolvimento de protótipo } \\
\text { para testes e ajustes. }\end{array}$ & $\begin{array}{l}\text { Desenvolvimento do material } \\
\text { gráfico (padrão cromático, } \\
\text { nome, marca, tipografia, } \\
\text { tabuleiro, peças, cartas e } \\
\text { embalagem) }\end{array}$ \\
\hline 6 & $\begin{array}{l}\text { Execução do projeto com } \\
\text { aplicação da identidade visual } \\
\text { e finalização para aplicação } \\
\text { do artefato. }\end{array}$ & $\begin{array}{l}\text { Execução do projeto com } \\
\text { aplicação da identidade visual } \\
\text { e finalização para aplicação } \\
\text { do artefato. }\end{array}$ & Avaliação do resultado. \\
\hline 7 & Avaliação & Avaliação & - \\
\hline
\end{tabular}

Os jogos desenvolvidos por estudantes do curso técnico (CTCD), fizeram parte dos projetos gráficos trabalhados na disciplina Projeto de Design e seguiram um roteiro adaptado da metodologia de Guillermo Ruiz, cujo enfoque dado é de Bruce Archer, descrito por Fuentes, (2006), onde o método é dividido em três fases: analítica, criativa e executiva. Na fase analítica, descritas nas etapas 1 e 2 do quadro acima, os estudantes formularam o briefing, definiram público e por meio de um brainstorming definiram a temática a ser trabalhada no jogo. Em seguida, efetuaram pesquisas de similares para definição de conceitos a serem explorados.

Durante a fase criativa, constantes nas etapas 3 e 4 do quadro, houveram experiências práticas com os estudantes testando vários tipos de jogos de tabuleiro, com temas, estratégias e dinâmicas diversas para auxiliar na formulação de ideias e definição de estratégias, jogabilidade 
e elementos compositivos do artefato, como identidade visual (padrão cromático, tipografia, elementos pictóricos, etc.), além de conceitos de diagramação e legibilidade na produção das regras, cartas e tabuleiro. Logo após, foram feitos os primeiros esboços.

Na última fase, citada nos itens 5, 6 e 7 do quadro, foi realizada a execução do projeto com desenvolvimento de protótipo para testes e ajustes, em seguida, a criação da identidade visual e finalização do jogo para ser aplicado. O projeto foi trabalhado em duas turmas (manhã e noite), sendo que cada turma foi dividida em 2 grupos para produção de 1 jogo cada grupo, no total de 4. O processo de avaliação deu-se da seguinte maneira: cada grupo experimentou, de forma prática, 3 jogos (exceto o seu) e respondeu questionário avaliativo sobre o que foi desenvolvido no que concerne à temática, jogabilidade, facilidade de entendimento das regras constantes no manual do jogo, legibilidade, entre outros itens. Ao final, eles ainda poderiam sugerir melhorias ou ajustes, caso julgassem necessário.

O jogo simulacro foi resultado de um TCC, do curso de graduação em design gráfico (AESO) e, a princípio, não segue uma metodologia padrão apesar de ter um procedimento metodológico dividido em etapas conforme descrição no quadro anterior. $\mathrm{Na}$ etapa 1 , define-se o briefing, objetivos e público-alvo, em seguida, na etapa 2, é feita uma pesquisa de similares e comparativos entre jogos de tabuleiro. Na etapa 3, foram definidos os elementos do jogo como: temática, conceitos, mecânica e jogabilidade. Logo após, na etapa 4, faz-se estudos para desenvolvimento de identidade visual sendo efetuada coleta de dados para geração das ideias. $\mathrm{Na} 5^{\mathrm{a}}$ etapa, efetua-se a aplicação da identidade desenvolvida, com a criação do material gráfico com justificativas para padrão cromático, nome, marca, tipografia, tabuleiro, peças, cartas e embalagem. É nesta etapa que o projeto se materializa. A avaliação é feita por meio de conclusões e análise sobre o desenvolvimento do projeto, não levando em consideração, especificamente, a sua aplicação. O autor do projeto ressalta a importância do design gráfico para esse tipo de projeto, indicando seu interesse em continuar pesquisando na área para o desenvolvimento futuro de novas pesquisas.

De modo geral, não existem metodologias específicas para o desenvolvimento de jogos didáticos, especificamente de tabuleiro. Existem procedimentos metodológicos que são utilizados pelos desenvolvedores para alicerçar o processo, contudo, esses métodos nem sempre são baseados em referências já existentes.

\section{Analise comparativa das metodologias DI - DJ}

A partir das descrições metodológicas, fizemos o cruzamento dos itens constantes em cada método utilizado para desenvolvimento dos jogos de tabuleiro, didáticos e não didáticos, para encontrarmos a presença das metodologias de design da informação nesses processos. Apesar de o design da informação não estar inserido diretamente em todo o processo, identificamos alguns pontos de convergência nos métodos trabalhados para o desenvolvimento desses artefatos.

\section{a. Familiarização com o tema}

Se familiarizar com o tema é relevante para os três autores mencionados nas metodologias de infodesign. Simlinger (2007), ressalta a importância de conhecer o ambiente onde o projeto vai ser apresentado. Por outro lado, nas metodologias de jogos didáticos (quadro 2) e design de jogos (quadro 3), a situação é diferente. Nas metodologias do quadro 2, a familiarização com o tema não tem essa priorização outorgada pelos autores em infodesign, pois o jogos já se desenvolveram inseridos dentro de um contexto específico: design e semiótica, química geral e geociências. Nas metodologias apresentadas no quadro 3, este tópico não é relevante durantes as etapas, pois a temática para desenvolver o jogo é escolha dos estudantes e o conhecimento do tema depende deles.

Anais [Oral] do 7º Congresso Internacional de Design da Informação | CIDI 2015

Proceedings [Oral] of the 7th Information Design International Conference / IDIC 2015 


\section{b. Definição do usuário}

A definição do usuário está presente nas metodologias apresentadas. Só na metodologia do quadro 2 apresentada por Mendes et al. (2009), a definição do usuário não esta implícita dentro do processo, o usuário tinha-se definido na formulação do projeto. Cabe ressaltar a diferença, do ponto de vista de design, a forma como se determina o usuário, pois nas metodologias de design da informação, se fala de usuário que é a definição de quem

vai usar ou fazer a ação. Já nas metodologias de jogos didáticos e design de jogos, menciona-se público-alvo, que é uma definição ou recorte da audiência, a partir de fatores demográficos, econômicos, gêneros, etc., ou seja, mais geral.

\section{c. Definição de elementos gráficos}

Os autores Sless (2005) e Simlinger (2007) enfatizam no uso de elementos que compõem o projeto, tais como: tipografia, cores, linguagem, layout e estrutura. Presente também nas metodologias de design de jogos, do CTCD (2013) na etapa 4 e em Albuquerque (2013) na etapa 5, como elementos compositivos do artefato.

\section{d. Projeto}

De acordo as metodologias de infodesign aqui descritas, Redish (2000) entende projeto como sendo parte das etapas a serem desenvolvidas no projeto como cronograma, orçamento, padronização etc. Sless tem uma abordagem próxima a de Simlinger (2007), tratando especificamente de como a informação será apresentada, utilizando diversos elementos para modelar o conteúdo da mensagem a ser transmitida. Na convergência com os jogos didáticos analisados (quadro 2), identificou-se que apenas o terceiro (Carneiro \& Lopes, 2007) descrevia a preocupação com as informações, utilizando o termo design no desenvolvimento dos materiais de suporte (físicos e gráficos). Os jogos não didáticos (quadro 3), por serem desenvolvidos por estudantes de curso de comunicação visual e design gráfico, apresentam essas definições no processo metodológico no que tange ao desenvolvimento de identidade visual, escolha de elementos gráficos e compositivos, além de aplicação de conceitos de diagramação e legibilidade.

\section{e. Testes / Avaliações}

Segundo os autores Redish (2000) e Sless (2005), os procedimentos metodológicos não dispensam testes com os usuários para diagnosticar e verificar como a informação está sendo apreendida, além de avaliação para identificar se os objetivos foram alcançados. Nos jogos didáticos de tabuleiro (quadro 2), a avaliação dos pesquisadores foi direcionada para o objetivo principal, transmitir determinado conteúdo trabalhado em aula por meio de atividade lúdica. Nos jogos de semiótica (Medeiros, 2013) observou-se que a falta de uma metodologia para desenvolvimento de jogos de tabuleiro, dificultou o processo em alguns momentos. No jogo direcionado ao ensino das geociências (Carneiro \& Lopes, 2007), onde foi empregado um método projetual, a avaliação foi positiva, com sugestão para ampliação da aplicação do jogo para público de áreas afins, como química e biologia.

Os esquemas que as metodologias apresentam são classificados segundo Bomfim (1995), em infodesign, como cíclicos (não lineares) e com retornos (feedbacks). Em jogos didáticos e design de jogos, identificamos um esquema tradicional, entendido como um modelo onde cada variável do problema é tratada isoladamente. As questões de familiarização com o tema, definição do usuário, definição de elementos gráficos, projeto e testes / avaliações são pontos de convergências encontrados entre as metodologias utilizadas, independente do método ou procedimento de cada pesquisador.

\section{Considerações finais}

Anais [Oral] do 7º Congresso Internacional de Design da Informação | CIDI 2015

Proceedings [Oral] of the 7th Information Design International Conference / IDIC 2015 
Nesta pesquisa, observamos que as metodologias de infodesign são pouco utilizadas no desenvolvimento de jogos didáticos de tabuleiro, em geral, pelo fato de os professores que desenvolvem esses artefatos não possuírem conhecimento, nem formação no campo do design. Os jogos de tabuleiro, para fins educacionais, são desenvolvidos a partir de um conhecimento pragmático na área de atuação do pesquisador sem, necessariamente, haver um método norteador. Dentro deste panorama de pesquisa, destaca-se a pesquisa-ação "do concreto ao virtual Interação e interatividade no letramento de indivíduos surdos" (COUTO, 2009), para o desenvolvimento de um jogo educativo aplicado ao ensino de LIBRAS, denominado Multi-Trilhas, cuja proposta está sintetizada em três etapas: problematização, proposta projetual e familiarização, que atendem aos pressupostos das metodologias de infodesign. Especificamente neste projeto, de acordo com as descrições sobre o desenvolvimento dos jogos de tabuleiro, encontramos a inserção do design da informação aplicado ao desenvolvimento de um artefato educacional.

Verificou-se, ainda, que algumas metodologias projetuais no campo do design, são utilizadas quando se trata de pesquisas e projetos, a partir dos experimentos, com estudantes da área de comunicação visual e design gráfico.

Acredita-se que a análise comparativa entre metodologias para desenvolvimento de jogos didáticos de tabuleiro, propõe novas perspectivas de pesquisas, como o cruzamento entre as metodologias de jogos didáticos, infodesign e design instrucional, já que tratamos de artefatos para fins educacionais. Consideramos, ainda, que o design da informação deve ser levado em conta, por ter uma preocupação mais ampla concernente ao projeto, onde de todos os atores envolvidos no desenvolvimento participam ativamente do processo e a necessidade do usuário está sempre norteando cada etapa. Com isso, as metodologias de infodesign são indicadas como forma de contribuição na elaboração de métodos para o desenvolvimento de jogos didáticos ou quaisquer artefatos educacionais.

\section{Referências}

ALBUQUERQUE, R. J. A. 2010. Simulacro: Criação de um jogo de tabuleiro. (Trabalho de conclusão de curso tecnologia em design gráfico não publicado). Faculdades Integradas Barros Melo. Olinda - PE.

BOMFIM, G. A. 1995. Metodologia para desenvolvimento de projetos. João Pessoa: Editora Universitária/UFPB.

CARNEIRO, C. D. R.; LOPES O. R. 2007. Jogos como instrumentos facilitadores do ensino de geociências: o jogo sobre "ciclo das rochas". Anais do I Simpósio de Pesquisa em Ensino e História de Ciências da Terra . III Simpósio Nacional Sobre Ensino de Geologia no Brasil. Unicamp.

CTCD, 2013.Notas de aulas do curso técnico em comunicação visual, disciplina Porjeto de Design, no Centro Tecnológico de Cultura Digital do Instituto de Tecnologia de Pernambuco ITEP/OS

COUTO, R. M. S. 2009. Do concreto ao virtual Interação e interatividade no letramento de indivíduos surdos. Relatório Final de Pesquisa Bolsa Modalidade Produtividade em Pesquisa. PUC-RJ.

FUENTES, R. 2006. A prática do design gráfico: uma metodologia criativa. São Paulo: Edições Rosari.

HURLBURT, A. 1981. The design concept. New York: Watson - Gup - till Publishers.

INFODESIGN. Revista científica publicada pela SBDI. Disponível em: http://www.infodesign. org.br/infodesign - acesso 1/7/2014.

Anais [Oral] do 7º Congresso Internacional de Design da Informação | CIDI 2015

Proceedings [Oral] of the 7th Information Design International Conference / IDIC 2015 
HORN, R. 1999. Information design: emergence of a new profession. In: JACOBSON, Robert (org.). Information Design, pp.16-17. Cambridge: MIT Press.

MEDEIROS, D. P. 2013. Design e Semiótica: a criação de jogos de tabuleiro como objetos de aprendizagem. Anais do XXI Simpósio Nacional de Geometria Descritiva e Desenho Técnico. Florianópolis-SC

MEDEIROS, D. P.; GONÇALVES, M. M. 2013. A Metáfora do jogo: relações entre metodologia projetual e jogos de tabuleiro. Anais do XXI Simpósio Nacional de Geometria Descritiva e Desenho Técnico. Florianópolis-SC

MENDES L. M.; TEIXEIRA, G.; OLIVEIRA, M. 2009. Desenvolvimento de jogos didáticos para as aulas de química geral do primeiro ano do ensino médio. Anais do IV CONNEPI - Congresso de Pesquisa e Inovação da Rede Norte e Nordeste de Educação Tecnológica. Belém-PA.

NEVES, A.; CAMPOS, F.; BENICIO, I. A.; MARISARDO FILHO; COUTINHO, G. S.; MARTINS, F. V. 2013. Design da informação nos jogos digitais. Anais do $6^{\circ} \mathrm{CIDI}$ - Congresso Internacional de Design da Informação / $5^{\circ}$ InfoDesign Brasil / $6^{\circ}$ Congic. Recife-PE.

PETTERSSON, R. 2012. It depends - Principles and Guidelines. Tullinge.

REDISH, J. 2000. What's information design? Technical Comunication Journal. Disponível em: http://dwheelersite.com/PDFs/Articles\%20for\%20Reading\%20List/Redish\%20 What\%20ls\%20I nformation \%20Design.pdf - acesso 1/7/2014.

SIMLINGER, P. 2007. Information Design: Core Competencies. What information designers know and can do. Disponível em: http://www.iiid.net/PDFs/idxPublication.pdf - acesso 26/7/2014.

SLESS, D. 2005. Designing for safety: a guide to my presentation. Disponível em: http://www. socap.org.au/files/3MJUHPNINY/David\%20Sless.pdf - acesso 1/7/2014.

\section{Sobre os autores}

Giselle Araújo, Professora, ITEP/OS, Brasil <giselletcaraujo@gmail.com>

Yelitza López, Mestranda, PPG Design UFPE, Brasil <yelitzalopezduque@gmail.com>

Solange Coutinho, PhD, UFPE, Brasil <solangecoutinho@globo.com>

Anais [Oral] do 7º Congresso Internacional de Design da Informação | CIDI 2015

Proceedings [Oral] of the 7th Information Design International Conference / IDIC 2015 